\title{
Expression of the Irisin Precursor FNDC5 in Skeletal Muscle Correlates With Aerobic Exercise Performance in Patients With Heart Failure
}

\author{
Stewart H. Lecker, MD, PhD; Alexandra Zavin, BS; Peirang Cao, PhD; Ross Arena, PhD, PT; \\ Kelly Allsup, BS; Karla M. Daniels, MS; Jacob Joseph, MD; P. Christian Schulze, MD, PhD; \\ Daniel E. Forman, MD
}

Background-Exercise-induced increase in peroxisome proliferator-activated receptor- $\gamma$ coactivator-1 $\alpha$ (PGC-1 $\alpha)$ expression has been shown to increase the expression of the fibronectin type III domain containing 5 (FNDC5) gene and thereby its product, irisin, in mice. Given that exercise intolerance is a hallmark characteristic of heart failure (HF), and because PGC- $1 \alpha$ and irisin promote exercise benefits in animals, we hypothesized that expression of these genes relates to aerobic performance in patients with HF.

Methods and Results - Systolic HF (left ventricular ejection fraction $\leq 40 \%$ ) patients underwent cardiopulmonary exercise testing to evaluate aerobic performance. High versus low aerobic performance was assessed using oxygen consumption (peak $\mathrm{Vo}_{2}\left[>14\right.$ versus $\left.\leq 14 \mathrm{~mL} \mathrm{O} \cdot \mathrm{kg}^{-1} \cdot \mathrm{min}^{-1}\right]$ ) and ventilatory efficiency $\left(\mathrm{VE} / \mathrm{Vco}_{2}\right.$ slope $[<34$ versus $\geq 34]$ ). Muscle biopsies of the vastus lateralis and real-time polymerase chain reaction were used to quantify muscle gene expression. Twenty-four patients were studied. FNDC5 $(5.7 \pm 3.5$ versus $3.1 \pm 1.2, P<0.05)$ and PGC- $1 \alpha(9.9 \pm 5.9$ versus $4.5 \pm 1.9$, $P<0.01)$ gene expressions were greater in the high-peak $\mathrm{Vo}_{2}$ group; correlation between FNDC5 and PGC-1 $\alpha$ was significant $(r=0.56, P<0.05)$ only in the high-peak $\mathrm{Vo}_{2}$ group. Similarly, FNDC5 and PGC-1 $\alpha$ gene expression was greater in the high-performance group based on lower $\mathrm{VE} / \mathrm{Vco}_{2}$ slopes $(5.8 \pm 3.6$ versus $3.3 \pm 1.4, P<0.05$ and $9.7 \pm 6$ versus 5.3 $\pm 3.4, P<0.05)$; FNDC5 also correlated with PGC- $1 \alpha(r=0.55, P<0.05)$ only in the low $\mathrm{VE} / \mathrm{Vco}_{2}$ slope group.

Conclusions - This is the first study to show that FNDC5 expression relates to functional capacity in a human HF population. Lower FNDC5 expression may underlie reduced aerobic performance in HF patients. (Circ Heart Fail. 2012;5:812-818.)

Key Words: heart failure $\square$ genes $\square$ physiology $\square$ biopsy

$\mathrm{E}_{\mathrm{f}}^{\mathrm{x}}$ xercise intolerance is a common complaint among heart failure (HF) patients. Although cardiac dysfunction contributes to HF symptoms, other mechanisms, including disease-related changes in skeletal muscle are also germane. ${ }^{1-3}$ Skeletal muscle abnormalities including altered metabolism, ${ }^{4}$ altered neurohormonal signaling, ${ }^{5}$ fiber-type shift toward increased anaerobic type II fibers, ${ }^{6}$ and endothelial dysfunction, ${ }^{7}$ are aspects of HF pathophysiology that have been linked to reduced peak oxygen consumption $\left(\mathrm{Vo}_{2}\right)^{8,9}$ and HF symptoms. ${ }^{10,11}$ Consistently, moderate-intensity aerobic exercise training, an intervention that does not substantially improve left ventricular ejection fraction, significantly improves the aerobic characteristics of skeletal muscle, along with improvements in peak $\mathrm{Vo}_{2}$ and clinical course. ${ }^{12-14}$ Therefore, better understanding of the biological determinants of skeletal muscle dysfunction in HF is of considerable importance as part of broader therapeutic goals to improve functional capacity and the related implications in respect to morbidity, mortality, and quality of life.

Physical activity promotes a more oxidative phenotype in skeletal muscle characterized by increased expression of the peroxisome proliferator-activated receptor $\gamma$ coactivator- $1 \alpha$ (PGC-1 $\alpha$ ). This transcriptional coactivator promotes mitochondrial biogenesis in skeletal muscle, which determines physiological and phenotypic changes. ${ }^{15}$ Irisin, a proteolytic hormone derivative (myokine) of the fibronectin type III domain containing 5 (FNDC5) gene, has been demonstrated in a mouse model to be induced by exercise (mediated by PGC$1 \alpha)$ and to then directly stimulate phenotypic changes in adipose tissue, which mediate changes in systemic metabolism. ${ }^{16}$

Received June 06, 2012; accepted September 04, 2012.

From the Division of Nephrology, Beth Israel Deaconess Medical Center (S.H.L., P.C.), and Division of Cardiovascular Medicine (K.M.D., D.E.F.), Brigham and Women's Hospital, Harvard Medical School, Boston, MA; New England Geriatric Research, Education, and Clinical Center (A.Z., K.A., J.J., D.E.F.), and Division of Cardiovascular Medicine (J.J., D.E.F), VA Boston Healthcare System, Boston, MA; Department of Orthopaedics and Rehabilitation - Division of Physical Therapy and Department of Internal Medicine - Division of Cardiology, University of New Mexico School of Medicine, Albuquerque, NM (R.A.); and Division of Cardiology, Columbia University Medical Center, New York, NY (P.C.S.).

The online-only Data Supplement is available at http://circheartfailure.ahajournals.org/lookup/suppl/doi:10.1161/CIRCHEARTFAILURE.112. 969543/-/DC1.

Correspondence to Daniel E. Forman, MD, Division of Cardiovascular Medicine, Brigham and Women's Hospital, 75 Francis St, Boston, MA 02115. E-mail: deforman@partners.org

(C) 2012 American Heart Association, Inc. 
As such, this newly identified hormone has the potential to become a therapeutic target that may improve functional performance that is often limited in HF patients. ${ }^{2,3}$

Although the initial description of FNDC5 expression and irisin production by Boström et $\mathrm{al}^{16}$ was made in mice, there is reason to believe that irisin also affects human physiology because the amino acid sequence of the molecule is identical between the species. It is theorized that FNDC5 may have similar roles in humans as in mice, but it is still not known how FNDC5 expression is controlled in human populations, or how it varies in different physiologic or pathophysiologic conditions.

In this analysis, we assessed PGC1- $\alpha$ and FNDC5 gene expression in relation to peak VO2 and the $\mathrm{VE} / \mathrm{Vco}_{2}$ slope, ${ }^{17}$ two well-established cardiopulmonary exercise test (CPX) measures of aerobic exercise performance. $\alpha$ and FNDC5 gene expression in relation to peak $\mathrm{Vo}_{2}$ and the $\left(\mathrm{VE} / \mathrm{Vco}_{2}\right)$ slope, two well-established cardiopulmonary exercise test (CPX) measures of aerobic exercise performance. This is a potentially important area of research particularly because of the notorious decrements of functional capacity seen among HF patients in association with skeletal muscle abnormalities. Reduced irisin may be a significant component of HF-related skeletal muscle changes that influence functional decline.

\section{Methods}

Clinically stable male systolic (left ventricular ejection fraction $\leq 40 \%$ ) HF patients aged $\geq 50$ years were enrolled. All were on a standard regimen of evidence-based HF therapy, including a $\beta$-blocker and angiotensin converting enzyme-inhibitor or angiotensin receptor blocker and were euvolemic at the time of assessment. In addition, each patient had an echocardiogram within 6 months of enrollment to confirm their left ventricular ejection fractions were $\leq 40 \%$ at the time of the study assessments. Mitral valve regurgitation was assessed based on trace, mild, moderate, or severe regurgitation (categorized as $0,1,2$, or 3, respectively) and is reported as an average. Patients were excluded if they had severe valvular disease, neurological disorders, pulmonary disease, or musculoskeletal problems, which could have confounded functional assessments. This study was approved by the local Veterans Affairs Institutional Review Board and all subjects signed an informed consent before participation.

\section{Aerobic Exercise Testing}

All patients performed a symptom-limited CPX test on a motorized treadmill (Bari-mill Woodway, Waukesha, WI) using a modified Balke protocol. ${ }^{18}$ The ventilatory expired gas analysis system (MedGraphics BreezeSuite St. Paul, MN) was calibrated according to manufacturer's specifications before each test. Continuous gas exchange, telemetry, blood pressure, rating of perceived exertion, and oxygen saturation were assessed for each patient 1 minute before, during, and 4 minutes after the exercise test in standard clinical fashion.

Both peak $\mathrm{Vo}_{2}$ and the $\mathrm{VE} / \mathrm{VcO}_{2}$ slope were used to assess aerobic performance. Just as peak $\mathrm{Vo}_{2}$ manifests both central (cardiac and pulmonary) and peripheral (skeletal muscle and peripheral vascular) physiologic processes, ${ }^{19,20}$ the $\mathrm{VE} / \mathrm{Vco}_{2}$ slope reflects a broad array of physiologic systems, including skeletal muscle chemo- and ergoreflexes and cardiopulmonary coupling. ${ }^{21-24}$

Aerobic indices including peak $\mathrm{Vo}_{2}$ (quantified as the highest 30 -second averaged value during the last stage of exercise) and the $\mathrm{VE} / \mathrm{VcO}_{2}$ slope were evaluated. $\mathrm{VE}$ and $\mathrm{VcO}_{2}$ values, acquired from the initiation of exercise to peak exercise (as 30-second averages), were entered into a spreadsheet software (Microsoft Excel, Microsoft Corp., Bellevue, $\mathrm{WA}$ ) to calculate the $\mathrm{VE} / \mathrm{VcO}_{2}$ slope via least squares linear regression $(\mathrm{y}=\mathrm{mx}+\mathrm{b}, \mathrm{m}=$ slope $)$. All subjects achieved a respiratory exchange ratio of $>1.0$ at peak exercise, an indication of good exercise effort. ${ }^{1}$

\section{Skeletal Muscle Biopsy}

Within 1 week after the CPX test, a skeletal muscle biopsy of the vastus lateralis muscle in the left leg was performed using a 5-mm Bergstrom muscle biopsy trochar. Biopsy samples were stored in RNALater (Qiagen, Valencia, CA) at $-80^{\circ} \mathrm{C}$ until gene-expression analyses were conducted.

\section{Gene-Expression Analyses}

Total skeletal muscle mRNA was extracted from muscle biopsies, using Trizol reagent according to the manufacturer's instructions. Total RNA was converted to cDNA by reverse transcription using SuperScript reverse transcriptase (Stratagene, Carlsbad, CA) and oligo dT primers in standard reactions according to the manufacturer's recommendations.

Gene-expression levels were determined from diluted cDNA samples (1:100) by real-time polymerase chain reaction using the StepOnePlus analyzer (Applied Biosystems, Foster City, CA). Multiplexed amplification reactions were performed using glyceraldehyde-3-phosphate-dehydrogenase as an endogenous control (glyceraldehyde-3-phosphate-dehydrogenase primers/VIC-labeled probe Applied Biosystems \# 4310884E) using the TaqMan Universal PCR Master Mix reagents Kit (\#4304437, Applied Biosystems). The following amplification settings were used: stage 1 (denaturation): $95^{\circ} \mathrm{C}$ for 10 minutes and stage 2 (polymerase chain reaction): $95^{\circ} \mathrm{C}$ for 15 seconds and $60^{\circ} \mathrm{C}$ for 60 seconds for 40 cycles. The threshold cycle values for each reaction were transferred to a Microsoft Excel spreadsheet and calculation of relative gene expression (to glyceraldehyde3-phosphate-dehydrogenase) was performed from this data according to published algorithms (TaqMan Cytokine Gene Expression Plate 1 protocol, Applied Biosystems). ${ }^{25}$ For each gene studied, all biopsy samples were analyzed on a single 96-well plate. Expression of the following genes were analyzed using FAM-labeled probe/primer sets purchased from Applied Biosystems: PGC-1 $\alpha$ (Hs01016724_m1) and FNDC5 (Hs00401006_m1).

\section{Statistical Analysis}

Statistical Analysis System (SAS) software version 9.0 (SAS, Cary, $\mathrm{NC}$ ) was used to analyze the data; values are reported as mean $\pm \mathrm{SD}$ unless otherwise indicated. The overall group was dichotomized into high versus low aerobic capacity according to clinically established thresholds for peak $\mathrm{Vo}_{2}\left(>14 \text { versus } \leq 14 \mathrm{~mL} \mathrm{O} \cdot \mathrm{kg}^{-1} \cdot \mathrm{min}^{-1}\right)^{19}$ and the $\mathrm{VE} / \mathrm{Vco}_{2}$ slope $(<34$ versus $\geq 34) .{ }^{26}$ Comparisons of high $\left(>14 \mathrm{~mL} \mathrm{O} \cdot \mathrm{kg}^{-1} \cdot \mathrm{min}^{-1}\right.$ or $\mathrm{VE} / \mathrm{Vco}_{2}$ slope $\left.<34\right)$ versus low $(\leq 14 \mathrm{~mL}$ $\mathrm{O}_{2} \cdot \mathrm{kg}^{-1} \cdot \mathrm{min}^{-1}$ or VE/ $/ \mathrm{Vco}_{2}$ slope $\geq 34$ ) performance among HF patients was determined using nonpaired $t$ tests, whereas evaluations of the correlation coefficients in the overall group as well as subgroups according to CPX performance were conducted by Pearson correlations. $P<0.05$ was used to define statistical significance for all tests.

\section{Results}

Twenty-four male systolic HF patients Twenty-four male systolic HF patients (mean age 67.2 \pm 9.2 years, age range 50-86) were evaluated. Mean left ventricular ejection fraction was $29.5 \pm 7.7 \%$, range $15 \%$ to $40 \%$.

Table 1 lists the patient characteristics for the entire cohort in the high versus low aerobic performance groups. Performance stratifications were based on peak Vo2 ( >14 versus $\leq 14 \mathrm{~mL}$ $\mathrm{O} 2 \cdot \mathrm{kg}^{-1} \cdot \mathrm{min}^{-1}\left[\mathrm{n}=15\right.$ and 9 , respectively] and $\mathrm{VE} / \mathrm{Vco}_{2}<34$ versus $\geq 34$ [n=14 and 10 , respectively]). ${ }^{19,26}$

Table 2 lists echocardiography and CPX aerobic indices. In general, patients had depressed systolic function by echocardiography but no differences between groups with respect to morphology or left ventricular function. Although pulmonary pressure (pulmonary artery systolic pressure [PASP]) was similar between the high- versus low-peak VO2 groups, 
Table 1. Key Demographic Characteristics

\begin{tabular}{|c|c|c|c|c|c|c|c|}
\hline & \multirow[b]{2}{*}{ Entire Cohort $(n=24)$} & \multicolumn{3}{|c|}{ Peak Vo ${ }_{2}\left(\mathrm{~mL} \mathrm{O}_{2} \cdot \mathrm{kg}^{-1} \cdot \mathrm{min}^{-1}\right)$} & \multicolumn{3}{|c|}{$\mathrm{VE} / \mathrm{NcO}_{2}$ Slope } \\
\hline & & $(n=15)$ & $(\mathrm{n}=9)$ & $P$ value & $(n=14)$ & $(n=10)$ & $P$ value \\
\hline Age, yr & $67.2 \pm 9.3$ & $64.7 \pm 7.1$ & $71.4 \pm 11.4$ & NS & $66.6 \pm 8.4$ & $68.1 \pm 11$ & NS \\
\hline Height, m & $1.7 \pm 0.07$ & $1.7 \pm 0.05$ & $1.7 \pm 0.1$ & NS & $1.7 \pm 0.05$ & $1.7 \pm 0.09$ & NS \\
\hline Weight, kg & $88.3 \pm 29.3$ & $87.7 \pm 19.3$ & $89.4 \pm 42.5$ & NS & $93.7 \pm 31.1$ & $80.7 \pm 26.1$ & NS \\
\hline $\mathrm{BMI}, \mathrm{kg} / \mathrm{m}^{2}$ & $29.3 \pm 7.8$ & $29.2 \pm 5.1$ & $29.6 \pm 11.3$ & NS & $31.1 \pm 8.7$ & $26.9 \pm 5.8$ & NS \\
\hline NT-proBNP & $1518.3 \pm 1810.5$ & $894.1 \pm 693$ & $2558.7 \pm 2575.9$ & NS & $1184.1 \pm 1668$ & $1986.1 \pm 1985.3$ & NS \\
\hline \multicolumn{8}{|c|}{$\begin{array}{l}\text { Medications ( } \mathrm{n} ; \% \\
\text { within each group) }\end{array}$} \\
\hline$\beta$-blocker & $18(75)$ & $11(73)$ & $7(78)$ & NS & $8(80)$ & $10(71)$ & NS \\
\hline ACE inhibitor & 19 (79.2) & $13(87)$ & $6(67)$ & NS & $8(80)$ & $11(79)$ & NS \\
\hline Statin & $20(83.3)$ & $13(87)$ & $7(78)$ & NS & $8(80)$ & $12(86)$ & NS \\
\hline ARB & $2(8.3)$ & $1(7)$ & $1(11)$ & NS & $1(10)$ & $1(7)$ & NS \\
\hline Diuretic & $17(70.8)$ & $9(60)$ & $8(89)$ & NS & $8(80)$ & $9(64)$ & NS \\
\hline \multicolumn{8}{|c|}{ NYHA classification } \\
\hline I & & 1 & 0 & NS & 1 & 0 & NS \\
\hline ॥ & & 10 & 6 & NS & 11 & 5 & NS \\
\hline III & & 4 & 3 & NS & 2 & 5 & NS \\
\hline
\end{tabular}

BMI indicates body mass index; NT-proBNP, N-terminal prohormone of brain natriuretic peptide; ACE, angiotensin converting enzyme; ARB, angiotensin (II) receptor blocker; $\mathrm{VO}_{2}$, oxygen consumption; $\mathrm{VE} / \mathrm{NCO}_{2}$, minute ventilation/carbon dioxide production; NS, not significant; and NYHA, New York Heart Association.

PASP level was significantly elevated in the low aerobic performance group assessed as $\mathrm{VE} / \mathrm{VcO}_{2}$ slope $\geq 34$.

When defining aerobic performance based on peak $\mathrm{Vo}_{2}$, the high-performance group was characterized by a peak $\mathrm{VO}_{2}$ of $17.0 \pm 3.0$ versus $11.4 \pm 1.6 \mathrm{~mL} \mathrm{O} \cdot \mathrm{kg}^{-1} \cdot \mathrm{min}^{-1}$ in the low-performance cohort, $P<0.0001$ (Table 2 ). When dichotomized into high and low performance according to the $\mathrm{VE} / \mathrm{Vco}_{2}$ slope, the high-functioning cohort demonstrated a significantly better ventilatory efficiency $(29 \pm 2.8$ versus $42 \pm 9.8, P<0.01)$.

Table 3 shows gene expression in relation to aerobic performance, and demonstrates significant differences between the two functional groups. shows gene expression in relation to aerobic performance, and demonstrates significant differences between the 2 functional groups. Subjects with higher aerobic performance indices, defined by either peak $\mathrm{Vo}_{2}>14$
$\mathrm{mL} \mathrm{O} \cdot \mathrm{kg}^{-1} \cdot \mathrm{min}^{-1}$, or by $\mathrm{VE} / \mathrm{Vco}_{2}$ slope $<34$, had significantly greater expression of both PGC- $1 \alpha$ and FNDC5. Within each of these 2 classifications of high-exercise performance, increased expression of FNDC5 correlated with greater expression of PGC- $1 \alpha$ (peak $\mathrm{Vo}_{2}>14 \mathrm{~mL} \mathrm{O} \cdot \mathrm{kg}^{-1} \cdot \mathrm{min}^{-1}, r=0.56, P<0.05$; $\mathrm{VE} / \mathrm{Vco}_{2}$ slope $\left.<34, r=0.55, P<0.05\right)$. Similar correlations between PGC-1 $\alpha$ and FNDC5 were not present in the lower functional groups (peak $\mathrm{Vo}_{2}<14 \mathrm{~mL} \mathrm{O} \cdot \mathrm{kg}^{-1} \cdot \mathrm{min}^{-1}, r=-0.22$, $P=0.58 ; \mathrm{VE} / \mathrm{Vco}_{2}$ slope $>34, r=0.47, P=0.17$ ). As demonstrated in Figure 1, FNDC5 expression correlated with PGC$1 \alpha$ expression in relation to the entire cohort $(r=0.61 P=0.001)$. Correlations between PGC- $1 \alpha$ and FNDC5 and peak $\mathrm{Vo}_{2}$ and the $\mathrm{VE} / \mathrm{Vco}_{2}$ slope are illustrated in Figure 2. Although all correlations trended in the expected direction, only the relationship between PGC- $1 \alpha$ and peak $\mathrm{Vo}_{2}$ reached statistical significance.

Table 2. Hemodynamic and Cardiopulmonary Indices

\begin{tabular}{|c|c|c|c|c|c|c|c|}
\hline & \multirow{2}{*}{$\begin{array}{l}\text { Entire } \\
\text { Cohort } \\
(n=24)\end{array}$} & \multicolumn{3}{|c|}{ Peak Vo ${ }_{2}\left(\mathrm{~mL} \mathrm{O}_{2} \cdot \mathrm{kg}^{-1} \cdot \mathrm{min}^{-1}\right)$} & \multicolumn{3}{|c|}{ VE/Vco ${ }_{2}$ Slope } \\
\hline & & $(n=15)$ & $(\mathrm{n}=9)$ & $P$ value & $(n=14)$ & $(n=10)$ & $P$ value \\
\hline \multicolumn{8}{|l|}{ Echocardiography parameters } \\
\hline LVEF, \% & $29.5 \pm 7.7$ & $28.6 \pm 8.4$ & $31.3 \pm 6.4$ & NS & $30 \pm 8.3$ & $29 \pm 7.4$ & NS \\
\hline LVIDd, cm & $5.8 \pm 0.8$ & $5.9 \pm 0.9$ & $5.7 \pm 0.8$ & NS & $5.8 \pm 0.9$ & $5.9 \pm 0.9$ & NS \\
\hline FS & $15.1 \pm 7$ & $16 \pm 7.6$ & $13.6 \pm 6.3$ & NS & $13.5 \pm 8.3$ & $17.1 \pm 4.7$ & NS \\
\hline PASP, $\mathrm{mm} \mathrm{Hg}$ & $26.5 \pm 7.7$ & $25.7 \pm 8$ & $27.7 \pm 7.8$ & NS & $21.9 \pm 7.4$ & $30.5 \pm 5.7$ & $<0.05$ \\
\hline MV regurgitation & $0.3 \pm 0.7$ & $0.2 \pm 0.6$ & $0.6 \pm 0.9$ & NS & $0.2 \pm 0.6$ & $0.6 \pm 0.9$ & NS \\
\hline \multicolumn{8}{|l|}{ Cardiopulmonary indices } \\
\hline Peak Vo ${ }_{2}, \mathrm{~mL} 0_{2} \cdot \mathrm{kg}^{-1} \cdot \mathrm{min}^{-1}$ & $14.9 \pm 3.3$ & $17.0 \pm 2.0$ & $11.4 \pm 1.6$ & $<0.0001$ & $16 \pm 3.1$ & $13.3 \pm 3.1$ & $<0.05$ \\
\hline $\mathrm{VE} / \mathrm{VCO}_{2}$ slope & $34.4 \pm 9.2$ & $30.1 \pm 3.8$ & $41.5 \pm 11.3$ & $<0.05$ & $29 \pm 2.8$ & $42 \pm 9.8$ & $<0.01$ \\
\hline Peak RER & $1.1 \pm 0.07$ & $1.1 \pm 0.1$ & $1.1 \pm 0.1$ & NS & $1.1 \pm 0.1$ & $1.1 \pm 0.1$ & NS \\
\hline
\end{tabular}

LVEF indicates left ventricular ejection fraction; LVIDd, left ventricular internal dimension at diastole; FS, fractional shortening; PASP, pulmonary artery systolic pressure; $\mathrm{MV}$, mitral valve; $\mathrm{Vo}_{2}$, oxygen consumption; $\mathrm{VE} / \mathrm{VCO}_{2}$, minute ventilation/carbon dioxide production; RER, respiratory exchange ratio; and $\mathrm{NS}$, not significant. 
Table 3. Gene Expression

\begin{tabular}{|c|c|c|c|c|c|c|c|}
\hline & \multirow{2}{*}{$\begin{array}{l}\text { Entire } \\
\text { Cohort } \\
(n=24)\end{array}$} & \multicolumn{3}{|c|}{ Peak Vo ${ }_{2}\left(\mathrm{~mL} \mathrm{O}_{2} \cdot \mathrm{kg}^{-1} \cdot \mathrm{min}^{-1}\right)$} & \multicolumn{3}{|c|}{ VE $/ \mathrm{NcO}_{2}$ Slope } \\
\hline & & $(n=15)$ & $(n=9)$ & $P$ value & $(n=14)$ & $(n=10)$ & $P$ value \\
\hline$P G C 1-\alpha$ & $7.9 \pm 5.4$ & $9.9 \pm 5.9$ & $4.5 \pm 1.9$ & $<0.01$ & $9.7 \pm 6$ & $5.3 \pm 3.4$ & $<0.05$ \\
\hline FNDC5 & $4.7 \pm 3.11$ & $5.7 \pm 3.5$ & $3.1 \pm 1.2$ & $<0.05$ & $5.8 \pm 3.6$ & $3.3 \pm 1.4$ & $<0.05$ \\
\hline
\end{tabular}

$P G C 1-\alpha$ and FNDC5 FNDC5 expression levels are given as mean \pm SD relative to the expression of glyceraldehyde 3-phosphate dehydrogenase performed in the same sample of CDNA.

$\mathrm{V}_{2}$ indicates oxygen consumption; $\mathrm{VE} / \mathrm{VcO}_{2}$ slope, minute ventilation/carbon dioxide production.

\section{Discussion}

This is the first study to show that expression of FNDC5, the genetic forerunner to irisin, may impact aerobic performance in HF patients and help to broaden our understanding of the biological determinants of exercise capacity and related cardiovascular health. Traditionally, the symptoms and progression of HF have been attributed solely to cardiac dysfunction and remodeling. Our findings regarding FNDC5 are part of an expanding literature demonstrating that skeletal muscle and other peripheral tissues mediate HF symptoms and pathophysiology. ${ }^{27-29}$ Although most HF patients lose muscle mass, leading to frailty and functional decline, the underlying mechanisms remain unclear. We demonstrate that expression in skeletal muscle of PGC- $1 \alpha$ and FNDC5 are higher and correlate to one another in a more functional HF cohort, in contrast to the lack of correlation in those who are functionally limited.

The recent identification of irisin, the product of the FNDC5 gene, suggests the presence of a hormonal pathway between muscle and adipose tissue, which may mediate some of the beneficial effects of exercise. Recent groundbreaking experiments in mice demonstrate that the transcriptional coactivator, PGC-1 $\alpha$, which promotes biogenesis of mitochondria, drives the expression of FNDC5, which in turn leads to increased brown adipose tissue, increased $\mathrm{Vo}_{2}$, insulin sensitivity, and glucose tolerance. ${ }^{16}$ Despite the known presence of irisin in human plasma, ${ }^{16}$ FNDC5 expression in the skeletal muscle of human systolic HF patients has not been previously reported.
Furthermore, our data are the first to correlate increased PGC-1 $\alpha$ and FNDC5 expression in subjects with higher aerobic performance characteristics, as defined by key CPX indices. These findings in human muscle are consistent with the data of Boström et $\mathrm{al}^{16}$ in mice linking muscle expression of PGC-1 $\alpha$ with FNDC5 expression. It seems likely that higher contractile activity in more aerobically fit HF patients promotes PGC-1 $\alpha$ and FNDC5 expression. A sensitive assay for identification of the irisin protein in human plasma is not yet available so we were unable to directly measure irisin levels in this patient cohort.

Peak $\mathrm{Vo}_{2}$ is considered the cornerstone of functional evaluation in HF patients and is assessed for quantification of disease severity and prognosis. ${ }^{19,20}$ However, ventilatory inefficiency (ie, the $\mathrm{VE} / \mathrm{VcO}_{2}$ slope) is also associated with increased risk for hospitalization ${ }^{30,31}$ and mortality ${ }^{24,32,33}$ through somewhat overlapping but different physiologic mechanisms. ${ }^{17}$ Although there are conflicting data regarding the optimal parameter for assessing functional capacity in HF patients, ${ }^{19,26,30}$ we show that regardless of the CPX parameter used for functional stratification, reduced performance is still associated with reduced PGC-1 $\alpha$ and FNDC5 expression. Consistently, in the lower-functioning study population subgroups, PGC- $1 \alpha$ expression did not correlate with FNDC5 expression, suggesting that the lack of signaling through these pathways may in part contribute to skeletal muscle

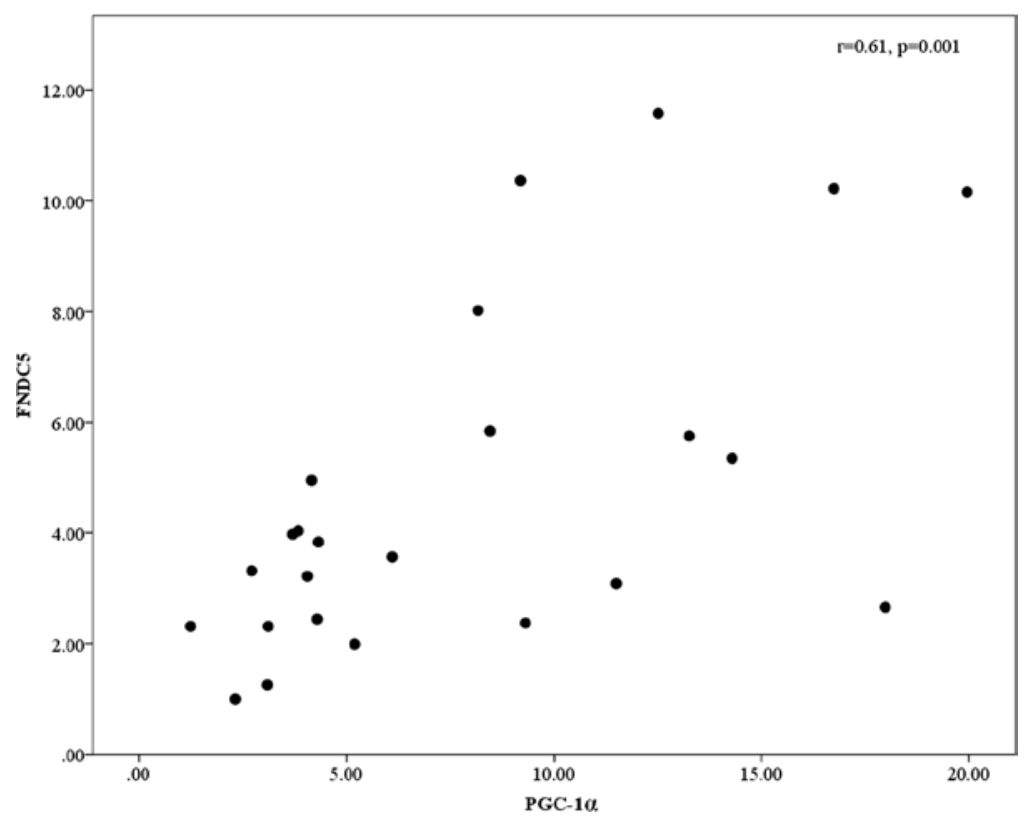

Figure 1. Correlation between FNDC5 and PGC$1 \alpha$ in the total study population. PGC1- $\alpha \alpha$ indicates peroxisome proliferator-activated receptor- $\gamma$ coactivator-1 $\alpha$; FNDC5, $\alpha$; and FNDC5, fibronectin type III domain containing 5 . 

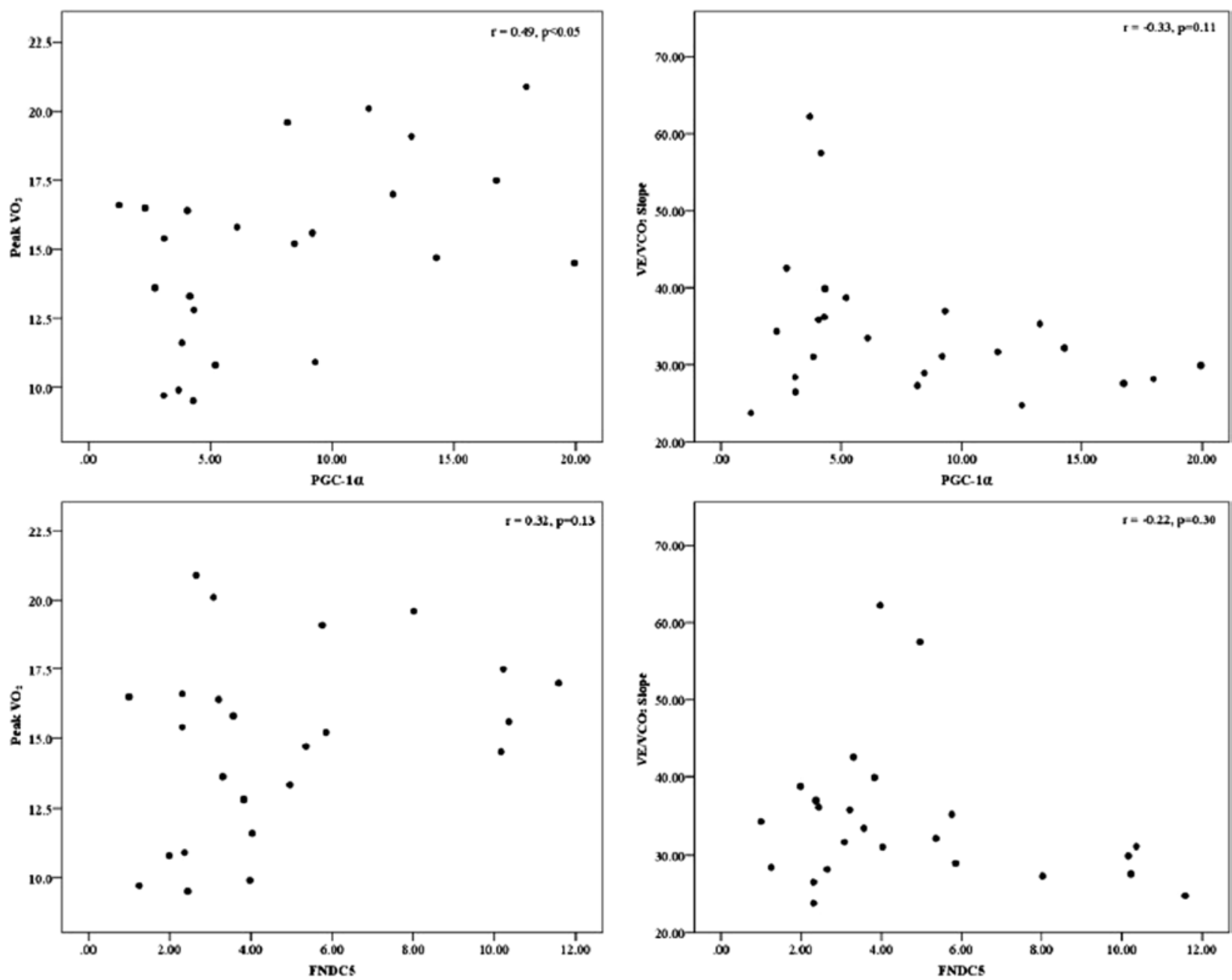

Figure 2. Scatter-plots demonstrating PGC1- $\alpha$ and FNDC5 in relation to peak $\mathrm{Vo}_{2}$ and the VE/Vco ${ }_{2}$ slope. PGC1- $\alpha \alpha$ indicates peroxisome proliferator-activated receptor- $\gamma$ coactivator- $1 \alpha$; FNDC5, $\alpha$; FNDC5, fibronectin type III domain containing 5; $\mathrm{MV}, \mathrm{mitral} \mathrm{valve;} \mathrm{Vo}_{2}$, oxygen consumption; $\mathrm{VE} / \mathrm{VCO}_{2}$, minute ventilation/carbon dioxide production; $\mathrm{Vo}_{2}$, oxygen consumption; and $\mathrm{VE} / \mathrm{VcO}_{2}$, minute ventilation/ carbon dioxide production.

abnormalities and functional decline among HF patients whose disease severity is at an advanced stage.

Notably, only PGC- $1 \alpha$ linearly correlated significantly with peak $\mathrm{Vo}_{2}$ (Figure 2), and the relationship was only modest. This finding indicates that although dichotomous classification of the cohort according to established peak $\mathrm{Vo}_{2}$ and $\mathrm{VE} /$ $\mathrm{VCO}_{2}$ slope thresholds (as stratifications of disease severity) seem to identify differences in FNDC5 and PGC- $1 \alpha$ expression, these same CPX variables do not seem to explain differences in FNDC5 and PGC-1 $\alpha$ in a linear, continuous fashion. If confirmed by future investigations in larger cohorts, these findings may lead to recommendations regarding CPX data application in relation to skeletal muscle physiologic assessments, ie, specific CPX thresholds of high versus low performance may be useful as key categories relative to which skeletal muscle physiology can be better understood and characterized.

Boström et $\mathrm{a}^{16}$ also suggest that irisin administration may have therapeutic benefits on glucose tolerance and obesity that mimic or amplify effects of exercise. Irisin may have particular benefits in a systolic HF population in which comorbidities such as obesity and insulin resistance are often present.
It is not yet known whether expression of FNDC5 is particularly low in these populations or if augmenting irisin levels in these patients will lead to clinical improvements. Although it is known that exercise can improve functional status in $\mathrm{HF}$ patients, it is likewise not yet known how FNDC5 expression changes with exercise training in these patients. Studies are currently underway to address these issues.

\section{Limitations}

A clear limitation of this study is the small sample size, but because the data reinforce and extend seminal principles published in recent animal studies it still stands out as an important addition to our understanding of irisin biology. Among the implications of a small study population, the degree of correlation between FNDC5 and PGC-1 $\alpha$ expression and each of the CPX measurements may have been affected. Thus, although we demonstrated differences of gene expression in relation to categorizations of high-aerobic performance based on peak $\mathrm{Vo}_{2}$ and $\mathrm{VE} / \mathrm{Vco}_{2}$ slope, it is not clear whether this reflects a physiologic distinction (such as disproportionate elevation of $\mathrm{VE} / \mathrm{VcO}_{2}$ slope despite similar peak $\mathrm{Vo}_{2}$ values in 2 HF patients based on differences in pulmonary pressures) 
or variance that is merely attributable to inadequate sampling. Additional research in larger cohorts is needed to further clarify these associations.

A related limitation is that a healthy control population was not included. While we considered comparing our findings with FNDC5 and PGC-1 $\alpha$ expression to a cohort without $\mathrm{HF}$, those without HF achieved much more favorable performance measures than $\mathrm{HF}$ patients (based on peak $\mathrm{Vo}_{2}$ and the $\mathrm{VE} / \mathrm{Vco}_{2}$ slope). Therefore in contrast to validated prognostic stratifications of peak $\mathrm{Vo}_{2}$ and the $\mathrm{VE} / \mathrm{Vco}_{2}$ slope for $\mathrm{HF}$, it was unclear how to stratify the much higher performance results of the non-HF cohort and to make meaningful comparisons to gene expression in HF patients.

More fundamentally, we were limited to assessments of FNDC5 expression as assays for irisin are not yet available, but conclusions regarding irisin based on FNDC5 are still physiologically robust. An additional limiting factor is that we have only assessed correlations between PGC- $1 \alpha$ and FNDC5 gene expression in functionally stratified $\mathrm{HF}$ patients and therefore cannot establish causality.

Influence of sex-specific variables, including hormonal influences, on gene expression and muscle metabolism may also be relevant. While we limited enrollment to male subjects to minimize confounding sex effects, evaluation of FNDC5 expression in females is needed in future investigations. Also, although there were no significant differences among patient demographic characteristics in the high-versus low-performance groups, this may be attributed to the small sample size than to true biological equivalence. N-terminal-pro B-type natriuretic peptide levels, for example, were substantially higher in the lower functioning groups (assessed by either peak $\mathrm{Vo}_{2}$ or the $\mathrm{VE} / \mathrm{Vco}_{2}$ slope). It is uncertain if this peptide is associated with or influences relative differences in PGC- $1 \alpha$ and FNDC5 gene expression.

\section{Conclusions}

The present investigation demonstrates that PGC- $1 \alpha$ and FNDC5 gene expression are increased in HF patients who have better aerobic performance, as indicated by the 2 primary CPX variables assessed in the HF population. Furthermore, PGC-1 $\alpha$ correlates with FNDC5 only in the higher-functioning groups.

\section{Sources of Funding}

This work was supported by the Veterans Affairs Merit Award (F4726R).

\section{Disclosures}

None.

\section{References}

1. Balady GJ, Arena R, Sietsema K, Myers J, Coke L, Fletcher GF, Forman D, Franklin B, Guazzi M, Gulati M, Keteyian SJ, Lavie CJ, Macko R, Mancini D, Milani RV; American Heart Association Exercise, Cardiac Rehabilitation, and Prevention Committee of the Council on Clinical Cardiology; Council on Epidemiology and Prevention; Council on Peripheral Vascular Disease; Interdisciplinary Council on Quality of Care and Outcomes Research. Clinician's Guide to cardiopulmonary exercise testing in adults: a scientific statement from the American Heart Association. Circulation. 2010;122:191-225.

2. Piepoli MF, Guazzi M, Boriani G, Cicoira M, Corrà U, Dalla Libera L, Emdin M, Mele D, Passino C, Vescovo G, Vigorito C, Villani G, Agostoni
P; Working Group 'Exercise Physiology, Sport Cardiology and Cardiac Rehabilitation', Italian Society of Cardiology. Exercise intolerance in chronic heart failure: mechanisms and therapies. Part II. Eur J Cardiovasc Prev Rehabil. 2010;17:643-648.

3. Piepoli MF, Guazzi M, Boriani G, Cicoira M, Corrà U, Dalla Libera L, Emdin M, Mele D, Passino C, Vescovo G, Vigorito C, Villani GQ, Agostoni P; Working Group 'Exercise Physiology, Sport Cardiology and Cardiac Rehabilitation', Italian Society of Cardiology. Exercise intolerance in chronic heart failure: mechanisms and therapies. Part I. Eur J Cardiovasc Prev Rehabil. 2010;17:637-642.

4. Mancini DM, Walter G, Reichek N, Lenkinski R, McCully KK, Mullen JL, Wilson JR. Contribution of skeletal muscle atrophy to exercise intolerance and altered muscle metabolism in heart failure. Circulation. 1992;85:1364-1373.

5. Berry C, Clark AL. Catabolism in chronic heart failure. Eur Heart J. 2000;21:521-532.

6. Clark AL, Poole-Wilson PA, Coats AJ. Exercise limitation in chronic heart failure: central role of the periphery. J Am Coll Cardiol. 1996;28:1092-1102.

7. Valgimigli M, Rigolin GM, Fucili A, Porta MD, Soukhomovskaia O, Malagutti P, Bugli AM, Bragotti LZ, Francolini G, Mauro E, Castoldi G, Ferrari R. CD34+ and endothelial progenitor cells in patients with various degrees of congestive heart failure. Circulation. 2004;110:1209-1212.

8. Piña IL, Apstein CS, Balady GJ, Belardinelli R, Chaitman BR, Duscha BD, Fletcher BJ, Fleg JL, Myers JN, Sullivan MJ; American Heart Association Committee on exercise, rehabilitation, and prevention. Exercise and heart failure: A statement from the American Heart Association Committee on exercise, rehabilitation, and prevention. Circulation. 2003;107:1210-1225.

9. Brassard P, Maltais F, Noel M, Doyon JF, LeBlanc P, Allaire J, Simard C, Leblanc MH, Poirier P, Jobin J. Skeletal muscle endurance and muscle metabolism in patients with chronic heart failure. Can J Cardiol. 2006;22:387-392.

10. Downing J, Balady GJ. The role of exercise training in heart failure. J Am Coll Cardiol. 2011;58:561-569.

11. Middelkauff H. Making the case for skeletal myopathy as the major limitation of exercise capacity in heart failure. Circ Heart Fail. 2010;3: 537-546.

12. Keteyian SJ, Piña IL, Hibner BA, Fleg JL. Clinical role of exercise training in the management of patients with chronic heart failure. J Cardiopulm Rehabil Prev. 2010;30:67-76.

13. Arena R, Myers J, Guazzi M. The clinical importance of cardiopulmonary exercise testing and aerobic training in patients with heart failure. Rev Bras Fioster. 2008;12:75-87.

14. Mandic S, Myers J, Selig SE, Levinger I. Resistance versus aerobic exercise training in chronic heart failure. Curr Heart Fail Rep. 2012;9:57-64.

15. Handschin C, Spiegelman BM. The role of exercise and PGC1alpha in inflammation and chronic disease. Nature. 2008;454:463-469.

16. Boström P, Wu J, Jedrychowski MP, Korde A, Ye L, Lo JC, Rasbach KA, Boström EA, Choi JH, Long JZ, Kajimura S, Zingaretti MC, Vind BF, Tu H, Cinti S, Højlund K, Gygi SP, Spiegelman BM. A PGC1- $\alpha$-dependent myokine that drives brown-fat-like development of white fat and thermogenesis. Nature. 2012;481:463-468.

17. Arena R, Myers J, Williams MA, Gulati M, Kligfield P, Balady GJ, Collins E, Fletcher G; American Heart Association Committee on Exercise, Rehabilitation, and Prevention of the Council on Clinical Cardiology; American Heart Association Council on Cardiovascular Nursing. Assessment of functional capacity in clinical and research settings: a scientific statement from the American Heart Association Committee on Exercise, Rehabilitation, and Prevention of the Council on Clinical Cardiology and the Council on Cardiovascular Nursing. Circulation. 2007; 116:329-343.

18. Balke B, Ware RW. An experimental study of physical fitness of Air Force personnel. U S Armed Forces Med J. 1959;10:675-688.

19. Mancini DM, Eisen H, Kussmaul W, Mull R, Edmunds LH Jr, Wilson JR. Value of peak exercise oxygen consumption for optimal timing of cardiac transplantation in ambulatory patients with heart failure. Circulation. 1991;83:778-786.

20. Sarullo FM, Fazio G, Brusca I, Fasullo S, Paterna S, Licata P, Novo G, Novo S, Di Pasquale P. Cardiopulmonary Exercise Testing in Patients with Chronic Heart Failure: Prognostic Comparison from Peak VO2 and VE/ VCO2 Slope. Open Cardiovasc Med J. 2010;4:127-134.

21. Saval MA, Kerrigan DJ, Ophaug KM, Ehrman JK, Keteyian SJ. Relationship between leg muscle endurance and (.) VE/(.)VCO2 slope in patients with heart failure. J Cardiopulm Rehabil Prev. 2010;30:106-110. 
22. Piepoli M, Ponikowski P, Clark AL, Banasiak W, Capucci A, Coats AJ. A neural link to explain the "muscle hypothesis" of exercise intolerance in chronic heart failure. Am Heart J. 1999;137:1050-1056.

23. Piepoli M, Clark AL, Volterrani M, Adamopoulos S, Sleight P, Coats AJ. Contribution of muscle afferents to the hemodynamic, autonomic, and ventilatory responses to exercise in patients with chronic heart failure: effects of physical training. Circulation. 1996;93:940-952.

24. Nanas SN, Nanas JN, Sakellariou DCh, Dimopoulos SK, Drakos SG, Kapsimalakou SG, Mpatziou CA, Papazachou OG, Dalianis AS, Anastasiou-Nana MI, Roussos C. VE/VCO2 slope is associated with abnormal resting haemodynamics and is a predictor of long-term survival in chronic heart failure. Eur J Heart Fail. 2006;8:420-427.

25. Livak KJ, Schmittgen TD. Analysis of relative gene expression data using real-time quantitative PCR and the 2(-Delta Delta C(T)) Method. Methods. 2001;25:402-408.

26. Chua TP, Ponikowski P, Harrington D, Anker SD, Webb-Peploe K, Clark AL, Poole-Wilson PA, Coats AJ. Clinical correlates and prognostic significance of the ventilatory response to exercise in chronic heart failure. $\mathrm{J} \mathrm{Am}$ Coll Cardiol. 1997;29:1585-1590.

27. Cicoira M, Zanolla L, Franceschini L, Rossi A, Golia G, Zamboni M, Tosoni P, Zardini P. Skeletal muscle mass independently predicts peak oxygen consumption and ventilatory response during exercise in noncachectic patients with chronic heart failure. J Am Coll Cardiol. 2001;37:2080-2085.
28. Piepoli MF, Kaczmarek A, Francis DP, Davies LC, Rauchhaus M, Jankowska EA, Anker SD, Capucci A, Banasiak W, Ponikowski P. Reduced peripheral skeletal muscle mass and abnormal reflex physiology in chronic heart failure. Circulation. 2006;114:126-134.

29. Ponikowski PP, Chua TP, Francis DP, Capucci A, Coats AJ, Piepoli MF Muscle ergoreceptor overactivity reflects deterioration in clinical status and cardiorespiratory reflex control in chronic heart failure. Circulation. 2001;104:2324-2330.

30. Arena R, Myers J, Aslam SS, Varughese EB, Peberdy MA. Peak VO2 and $\mathrm{VE} / \mathrm{VCO} 2$ slope in patients with heart failure: a prognostic comparison. Am Heart J. 2004;147:354-360.

31. Arena R, Humphrey R. Comparison of ventilatory expired gas parameters used to predict hospitalization in patients with heart failure. Am Heart J. 2002; 143:427-432.

32. Francis DP, Shamim W, Davies LC, Piepoli MF, Ponikowski P, Anker SD, Coats AJ. Cardiopulmonary exercise testing for prognosis in chronic heart failure: continuous and independent prognostic value from $\operatorname{VE} / \operatorname{VCO}(2)$ slope and peak VO(2). Eur Heart J. 2000;21:154-161.

33. Arena R, Myers J, Hsu L, Peberdy MA, Pinkstaff S, Bensimhon D, Chase P, Vicenzi M, Guazzi M. The minute ventilation/carbon dioxide production slope is prognostically superior to the oxygen uptake efficiency slope. J Card Fail. 2007;13:462-469.

\section{CLINICAL PERSPECTIVE}

Exercise intolerance is a common symptom among heart failure (HF) patients with profound clinical ramifications. Both central (cardiac output, alveolar perfusion) and peripheral (skeletal muscle, capillary perfusion) mechanisms have been implicated. Moderate-intensity aerobic exercise training typically improves functional capacity with little or no impact on central cardiac parameters, highlighting the importance of peripheral physiology on HF management. Nonetheless, pertinent $\mathrm{HF}$ effects on skeletal muscle remain poorly defined. Aerobic exercise training has been demonstrated to induce a more oxidative skeletal muscle phenotype, characterized by increased expression of the transcriptional coactivator peroxisome proliferator-activated receptor- $\gamma$ coactivator- $1 \alpha(\mathrm{PGC}-1 \alpha) \alpha)$ and mitochondrial growth. Recent animal studies have also demonstrated that irisin, a newly described myokine, is induced by exercise through the action of PGC-1 $\alpha$ to stimulate changes in adipose tissue that mediate improvements in systemic metabolism. We hypothesized that expression of PGC-1 $\alpha$ and FNDC5 (the genetic precursor of irisin) relates to aerobic performance in human HF patients. We measured aerobic capacity (cardiopulmonary exercise testing indices peak oxygen consumption and ventilatory efficiency slope) in 24 patients with systolic HF (left ventricular ejection fraction $\leq 40 \%$ ). We assessed PGC-1 $\alpha$ and FNDC5 from skeletal muscle biopsies. We demonstrate that PGC-1 $\alpha$ and FNDC5 gene expressions are greater in the patients with the greater functional capacity (peak oxygen consumption $>14 \mathrm{~mL} \cdot \mathrm{kg}^{-1} \cdot \mathrm{min}^{-1}$, ventilatory efficiency slope $<34$ ). This is the first study to show that irisin expression correlates with functional capacity in HF patients. Lower FNDC5 expression may underlie reduced aerobic performance in HF. 


\section{Expression of the Irisin Precursor FNDC5 in Skeletal Muscle Correlates With Aerobic Exercise Performance in Patients With Heart Failure}

Stewart H. Lecker, Alexandra Zavin, Peirang Cao, Ross Arena, Kelly Allsup, Karla M. Daniels, Jacob Joseph, P. Christian Schulze and Daniel E. Forman

Circ Heart Fail. 2012;5:812-818; originally published online September 20, 2012; doi: 10.1161/CIRCHEARTFAILURE.112.969543

Circulation: Heart Failure is published by the American Heart Association, 7272 Greenville Avenue, Dallas, TX 75231

Copyright (C) 2012 American Heart Association, Inc. All rights reserved.

Print ISSN: 1941-3289. Online ISSN: 1941-3297

The online version of this article, along with updated information and services, is located on the World Wide Web at:

http://circheartfailure.ahajournals.org/content/5/6/812

\footnotetext{
Permissions: Requests for permissions to reproduce figures, tables, or portions of articles originally published in Circulation: Heart Failure can be obtained via RightsLink, a service of the Copyright Clearance Center, not the Editorial Office. Once the online version of the published article for which permission is being requested is located, click Request Permissions in the middle column of the Web page under Services. Further information about this process is available in the Permissions and Rights Question and Answer document.
}

Reprints: Information about reprints can be found online at: http://www.lww.com/reprints

Subscriptions: Information about subscribing to Circulation: Heart Failure is online at: http://circheartfailure.ahajournals.org//subscriptions/ 